\title{
Avoid Fraud During Emergencies ${ }^{1}$
}

Mary Harrison ${ }^{2}$

\section{Situation}

When there is an emergency situation most people strive to be helpful to others. But, there are a few individuals who will take advantage of the situation and use it for personal gain by victimizing others.

\section{Opportunity for Fraud}

The fear of terrorist attacks is a new experience for Americans. The lack of experience with such events leaves many people feeling confused, insecure and vulnerable. These kinds of feelings makes a person more susceptible to deception and fraud. Con artists use any type of emergency, from hurricanes, floods to terror; to play on our fears and emotions to get us to buy overpriced, worthless or unneeded goods and services. They use pressure sales tactics and insist on immediate action.

\section{Your Defense}

Your best defense against terror is a healthy skepticism. Remain calm so you are able to make rational decisions:

- Get information from unbiased, reliable sources.

- Check accuracy of claims by sellers or promoters by contacting other sources. Compare reliability of claims.

- Do not let anyone pressure you into making instant decisions.

- Be very skeptical of any claims that promise unrealistic results (miracles are not marketed).

\section{Potential Frauds}

When there are periods of high concern, scams appear. The nation is concerned about terror. The unethical will develop scams to fleece people of their money. Con artists use fear and most scams will relate to protection from injury or survival. Look for things such as these examples:

- Sale of gasmasks which are over priced, supposed to protect against all types of chemicals.

- Bulletproof vests, clothing, designed to protect against all types of explosives.

- Devices to keep in touch with relatives regardless of conditions.

- A device to sound an alert anytime a toxic substance appears.

- Care kits, to use when evacuating.

- Home safety kits, to keep pollutants out.

- And many others.

1. This document is FCS9193, one of a series of the Department of Family, Youth and Community Sciences, Florida Cooperative Extension Service, IFAS, University of Florida, Gainesville FL 32611: First published: May 2003. Reviewed by Elizabeth Bolton, Ph.D., Department of Family, Youth and Community Sciences. Please visit the EDIS Web site at http://edis.ifas.ufl.edu

2. Mary Harrison, M.S., professor, Department of Family, Youth and Community Sciences, University of Florida, Gainesville FL 32611. 
If there are property attacks the scams will target concerns relating to cleanup and rebuilding. Fraud will include shoddy, overpriced cleanup work, unqualified builders, unethical lenders, overpriced credit, etc.

\section{Protections}

You are your own best protection. Although there are laws that provide many protections con artists usually take advantage of their victims and then disappear. Report any illegal action to regulatory authorities. However, you are much better off to avoid being victimized. 